\section{Changes to financial incentives in English dentistry 2006-2009: a qualitative study}

Mcdonald R, Cheraghi-Sohi S, Sanders C, Tickle M. Changes to financial incentives in English dentistry 2006-2009: a qualitative study. Community Dent Oral Epidemiol 2012 (C) 2012 John Wiley \& Sons AS

Abstract - Objectives: To explore the views of NHS dentists in England regarding reforms, which changed their incentive and payment structure. Methods: Semi-structured interviews with 35 dentists, digitally recorded, transcribed verbatim and analysed using a constant comparative method. Results: Dentists reported changing their behaviour in response to incentives in ways that were likely to have adverse impacts on patients. There was also a loss of trust in NHS paymasters, as well as a loss of faith in the ability to provide high quality care in NHS dentistry. Conclusions: Responses suggest that many dentists were quick to change behaviour following the introduction of a revised contractual structure in 2006. The coalition government in the UK has stated its intention to introduce a new NHS dental contract. Our data suggest that part of the process of changing behaviours, norms and attitudes will require the rebuilding of trust in the NHS amongst NHS dentists, as opposed to merely redesigning incentive structures, though the two are related.
Ruth Mcdonald ${ }^{1}$, Sudeh Cheraghi-Sohi ${ }^{2}$, Caroline Sanders ${ }^{3}$ and Martin Tickle ${ }^{4}$

${ }^{1}$ University of Nottingham, Nottingham, UK, ${ }^{2}$ University of Manchester, Manchester, UK, ${ }^{3}$ Primary Care, University of Manchester, Manchester, UK, ${ }^{4}$ School of Dentistry, University of Manchester, Manchester, UK
Key words: clinical; clinical decision making; disparities; Evidence Based Dentistry(EBD); health services research; psychosocial aspects of oral health; public health policy; public policy; qualitative research

Ruth Mcdonald, University of Nottingham, B18c, Sir Colin Campbell Building, Triumph

Road, Nottingham, UK

Tel.: +44(0)115 8230588

Fax: $+44(0) 1158466667$

e-mail: ruth.mcdonald@nottingham.ac.uk

Submitted 27 April 2011;

accepted 12 February 2012
In recent years, increasing emphasis has been placed on the use of financial incentives to influence behaviours of health professionals. Whilst it may be desirable to align payment mechanisms with policy goals, the potential for financial incentives to result in unintended behaviour is well documented (1). A key criticism of financial incentives is that they may diminish or eradicate intrinsic motivation (i.e. the desire to do something for its own sake) (2). Furthermore, an additional concern is that incentives may have unintended consequences for patients $(3,4)$. However, it has been argued that amongst health professionals, altruistic behaviours will mitigate the impact of potential negative consequences (5).

There is a large and growing literature outlining the impacts of incentives on professional behaviours; the majority of this in the health field is concerned with doctors. In this paper, we explore the consequences of an initiative to change the incentive structure facing dentists. In particular, our aim is to outline responses to a new contract for NHS dentists in England, which was introduced in 2006.

Prior to the changes to the incentive structure, the major part of the dental contract was based on fee for item but contained an element of capitation, restricted to children, which was intended to encourage registration and promote continuity of care and responsibility for maintenance of the patient's oral health. The pre-2006 dental contract was a national contract with little local NHS managerial input into the provision of services. Individual dentists had a high degree of autonomy.

Under the new contract introduced in 2006, registration ceased to exist, and along with it, the contractual responsibility for dentists to provide out of hours cares for their patients. A new contract currency Units of Dental Activity (UDAs) was introduced. This grouped treatments into three bands replacing some 400 fees for individual treatment items together with a corresponding new banded patient charging system. Each contractor was given 
an annual target of UDAs, and a price per UDA, based on their historical earnings and activity under the old contract less $4 \%$. As part of the contract reform process, responsibility for planning and securing NHS dental services was devolved to local Primary Care Trusts (PCTs), whose staff commission care for their respective populations. Providers (owners of dental practices) now enter into contracts with local PCTs, and payment is based on 12 fixed monthly payments per year rather than an open-ended commitment to pay dentists fees for items of service delivered.

\section{Methods}

\section{Design and setting}

This qualitative, exploratory and descriptive study was carried out in one English region (North West). Although there were reports in the press that dentists were unhappy with the new working arrangements, little research has been conducted, which examines dentists' views and attitudes. We undertook an exploratory study, therefore, to investigate these and to assess the likely impact on patient oral health. The study was approved by Leeds East NHS Ethics Committee.

\section{Participants}

We interviewed dental providers and performers; the latter group are dentists who are self-employed and work within a provider's practice according to a privately agreed contract with the provider that involves paying a significant proportion of their income (usually around 50\%) for use of a surgery, materials and support staff. Our intention was to interview both provider and performer dentists more than once over a 3-year period to assess initial responses and any changes in these over time. (We use the designation R2 to denote quotes from a second interview). Recruitment proved difficult, so we adopted a process of snowballing, whereby a small number of initial participants put the researchers in touch with others, who then nominated colleagues and other contacts, and so on (6). A limitation of this approach, however, is that the sample may be more negatively predisposed to the 2006 contract than the general dental practice population, because those with grievances to air may be more willing to consent to participate.

\section{Data collection}

The interviews were conducted by three of the authors (SCS, RM, CS), all of whom are social scientists and experienced researchers. Dentists were aware that interviewers were not dental practitioners. The interviews were conducted as part of a wider, longitudinal, study examining motivation and incentives more generally. Therefore, the schedule was open-ended and addressed reasons for entering dentistry, likes and dislikes about work, and attitudes towards and impact of contract reforms on practice. This was piloted with one dentist prior to its use.

First-round interviews were conducted between November 2007 and October 2008. We were able to interview a total of 25 providers ( $23 \mathrm{men}$ ) and 10 performers (four men) during this period. All of these interviews were conducted on a face-to-face basis. For our second-round interviews, many dentists declined to participate, because of pressure of work; four had left their practices (three performers and one provider). Of our initial participants, we interviewed 15 (12 providers) twice and we recruited 10 new participants giving a total of 18 providers (17 men) and seven performers (two men). All of these 25 s-round interviews took place between May and November 2009, and all but five of these, which were telephone interviews, were face to face. Interviews continued beyond the point at which data saturation was achieved. This was partly because of interviews having been arranged in advance and also ensured that additional interviews yielded no new themes. It also provided an opportunity to examine any changes of opinion in the second round of interviews. However, no such changes were identified. All interviews were audio recorded and transcribed verbatim, and all were conducted in the participants' place of work.

\section{Data analysis}

The authors read all transcripts independently, using a constant comparative method to interpret the data (7). Key concepts were identified using an open-coding method, with transcripts coded manually. Once coding was complete, the codes that had common elements were merged to form categories. One of the authors (MT) is a qualified dental practitioner who had knowledge and experience of the dental contract, prior to the commencement of the research. At times, there were disagreements about interpretation of the data, in part because of this author's perspective being influenced by his prior experiences. For example, this author was less inclined to empathize with dentists and more likely than the other authors to view dentists' desire to expand their private 
practice as because of factors beyond the contract, such as seeking to reduce their accountability to third party payers and wanting to increase profitability. Disagreements were discussed until a consensus was achieved. This process involved meeting to discuss relevant data extracts, challenging assumptions that were not supported by or explicit in the data and constraining interpretation to exclude prior assumptions. It also involved reaching a shared understanding that reporting dentists' views (the subject of this paper) was not the same as accepting that dentists' accounts necessarily represent an objective 'truth' about the nature and fairness or otherwise, of the dental contract.

\section{Results}

As the focus of this paper was on responses to the new contract, we present data that relate to that topic, derived from the coding categories developed under three headings.

\section{Attitudes to NHS and private practice}

Dentists depicted private practice as releasing them from the treadmill of NHS dentistry, resulting in an improved quality of treatment for patients.

You see some people who have got absolutely superb dental work, A-one, top quality .... And you think, 'Hmm, they must have been done privately,' because we can't spend all this time in NHS. [25R2 (provider)]

Amongst almost all of our dentists, there was agreement that at least some element of private practice was preferable to being wholly dependent on PCT contract income.

if you've got private, then you might control yourself again.... rather than somebody at the PCT saying, 'You ought to do this, because we've decided.' If you're private, then you can do what you want and what you think is best, rather than what someone else thinks is best. [22 (provider)]

Dentists described the NHS contract as constraining autonomy in a number of ways. The fact that target treatment volumes were specified in advance, with money clawed back for underperformance, was described as requiring a focus on contract targets, rather than quality of care. Dentists also reported that contract values were imposed on them and that the uncertainty surrounding future contracts was a source of anxiety. The contract introduced a ban preventing dentists from charging patients who failed to attend for appointments. This constrained dentists' ability to run their practice as they saw fit and at the same time made the achievement of targets more difficult.

We've got no control... we can't charge people for not turning up. We used to charge NHS patients for not turning up, and we had about $1.5,2 \%$ failure rate. We've now got a $15,20 \%$ failure rate....They want to tell us who we see, when we see them, the sort of patients we see and basically dictate to us what we do in our own businesses. ...we've sunk half a million pounds into this business. It's our business. They want control of it. They now want to put the NHS logo outside if you've got a contract. I don't want my business to look cheap. I don't want an NHS logo outside. [8 (Provider)]

With regard to the issue of balancing ethical or altruistic concerns and income, the contract reforms appeared to have reduced or eliminated some of the dilemmas facing dentists. For example, dentists reported no qualms about refusing to take on new NHS patients on the grounds that the remuneration for treating such patients was unlikely to cover costs and spending a lot of time on such patients would reduce resources to deliver contract UDA targets. Dentists referred to this as being common practice, which suggests an implicit agreement amongst members of the profession. This may act to bolster the legitimacy of such actions, rather than creating concerns about the extent to which the demands of running a business might compromise professional standards.

we tend to sort of decline to see new patients because we are frightened... until you examine them, you don't know what you're taking on board. [27 (provider)]

More generally, the contract was described as bringing dentists together as part of a common response of both opposition and fear, which may also contribute to the development and legitimation of a collective antipathy to NHS practice.

We didn't used to have colleagues, we used to have competitors and it was very much everyone was in competition with everybody else.... Out of sheer terror it's brought people together, 
at least to kind of huddle together for safety, as it were [1(provider)].

\section{Role of performers}

Although performers do not hold PCT contracts and in effect rent surgeries and staff time from providers, they were very aware of the targets and constraints contained in the 2006 contract. This is understandable because many providers reported shifting towards UDA-based contracts with performers rather than taking a percentage of their earnings.

My new associate (performer) .... gets paid per UDA. ...he will adjust appointment times accordingly. [18R2 (provider)]

I asked her [performer] to leave, yes....I had asked her to leave. We weren't achieving targets. [2R2 (provider)]

In many cases, performers were tasked by providers specifically to undertake NHS work, with providers choosing to focus, where possible, on private work. This meant that performers were very aware of the changes to the regime and its implications for NHS patients as well as for their practice.

it's a shame really .... people are getting probably a much poorer treatment than they could have got under item of service [old payment system]....they're just going to get extractions and dentures because once you start getting above two and three crowns it really does become a loss. And at the end of the day whilst we are, working in a Health Service Contract, it also is how we make a living. [43 (performer)]

Although performers did not have direct contact with PCT contract staff, they were very aware of the terms of the contract and generally viewed it as unfair.

\section{Perverse incentives and professional behaviour} The 2006 contract caps income, and it contains perverse incentives to base treatment decisions on financial rather than clinical factors. There are incentives to stage treatments to claim for discrete elements as new courses of treatment. Doing so would increase income but also require patients to pay higher charges compared with providing services as part of a single course of treatment.

if a patient comes in and just needs one filling doing, you get three UDAs.... If a patient comes in and they need every tooth in their head filled... three UDAs. So what do some of these youngsters do ......but us as well, do one filling, then get back in a few months time and then do another. (emphasis added) [17 (provider)]

Additionally, the replacement of some 400 fees for individual treatment items, with three UDAs bands, creates incentives to shift to treatments where rewards relative to effort are high. In some cases, dentists reported referring patients to hospital rather than treat them at a loss. This would at least enable the tooth to be saved.

molar root treatments....you get three UDAs for them, and you could be spending two hours trying to get all the nerve out and root filled..... that's just not financially viable to do that, so we send them over to the dental hospital, but there's the waiting list. [21 (provider)]

However, dentists also freely admitted to taking advantage of the perverse incentives afforded by the new system and removing the tooth rather than spending time and effort to preserve it.

a molar root canal treatment done to the standard that we're supposed to work to would normally take about an hour and a half of treatment time. And I could take the tooth out and get the same number of UDAs. Which do you think we would suggest...? Both will achieve the same result. Both will get the patient out of pain. [21 (provider)]

Crown and bridgework all require expensive support from dental laboratory services. Dentists are paid a standard number of UDAs (12 UDAs for crowns, regardless of the number carried out), even though each procedure requires laboratory work that incurs costs for the dentist. This was also resulting in dentists making treatment decisions based on costs and income rather than on patient preferences or clinical factors.

I'm not likely to be offering a bridge, where I used to offer a bridge. Purely because it's costing me more in lab work and it's just the nature of the beast. Yes, we should do it, but human nature tells you why are we going to be spending a lot of money on lab work? It'll be more in the payments I'm paying out, than I'm actually getting in the UDAs.[18 (provider)]

As the comments mentioned above suggest, basing treatment decisions on business considerations 
was viewed as 'human nature' and a perfectly understandable response to the imposition of a very unfair system, rather than 'unprofessional' behaviour and performers were not immune from such behaviour.

\section{Discussion}

Under the old items of service contracts, dentists faced financial incentives to increase activity to generate more income. Making treatment decisions based on remuneration rather than clinical factors is at odds with a notion of professionalism as bound up with altruistic concerns. We found that dentists justified a shift towards private practice in terms of both benefits to patients and autonomy. The revised patient charges introduced as part of the contract resulted in some NHS patients facing higher charges relative to private practice. Even amongst dentists whose practice was almost entirely NHS, NHS practice was seen as detrimental in terms of fees, income, time and autonomy.

Whilst public sector dentistry couples public service values and vocation to professionalism, private sector care is viewed as offering better service in terms of treatment options, as well as respecting professional autonomy. Furthermore, in combination with the revised patient charge bandings, which can result in patients being charged more for NHS treatment, these factors appear to create a conflict between the business of NHS dentistry and professionalism. The issue of professionalism in the context of the changing nature of NHS dentistry is very pertinent to the perverse incentives contained in the contract and the potential dilemmas, with regard to professional standards, which these create.

The GDC's definition of professionalism includes putting patients' interest first and respecting their dignity and choices. Yet in response to a target system whose payment rules were described as too crude to provide adequate rewards for high levels of effort, dentists freely admitted to basing treatment decisions on financial, rather than clinical, factors. Rather than describing such circumstances as creating ethical dilemmas or suggesting that such temptations were resisted, dentists reported these actions as being a necessary aspect of practice to survive under the rules of the 2006 contract. Although the previous contract contained incentives to select treatments to maximize income, dentists did not readily admit to responding to perverse incentives (5). However, following the intro- duction of the 2006 contract, dentists' responses suggest that being a professional under the new payment regime appears to be defined in terms of understanding the rules and tailoring one's practice to them to remain in business, suggesting a clear conflict between business, according to the new NHS contract and traditional definitions of professionalism in dentistry. Private practice was also depicted as enabling better quality treatment generally and more specifically, more appropriate treatment, in a context free from UDA targets. So a shift away from NHS treatment does not necessarily suggest support for a view of professionalism as bound up with self-interest and financial gain.

Dentists admit to choosing extraction over preservation and more generally to shifting towards treatments for which rewards are high relative to effort, findings supported by empirical evidence (8). This suggests that it is the interests of dentists, as opposed to patients, which are being prioritized.

Our findings of resentment and frustration resonate with a recent survey that reported the reforms as having a negative impact on dentists' job satisfaction and morale (9). The view of the contract as flawed and impacting adversely on access to dental services had also received support from a Health Select Committee report (10) and a recent independent review of the contract (11). This recommended a new contract, with a proportion of payments made for activity to incentivize provision of treatment and a proportion of the contract to pay for quality to improve access, provide effective preventive care and ensure continuity of care. At the same time, newspaper headlines reporting the high incomes of providers ('one in every 30 dentists earning more than a quarter of a million pounds' (12)) suggest that these dentists are able to make a good living under the 2006 contract, although as we describe, there are unintended consequences associated with this. Although performers are reported as earning much less than providers (13), we did not detect any resentment from the former group towards the latter. In part, this may be due to performers making tradeoffs between income and quality of life, by avoiding business ownership. These figures do suggest also that it might be in the interests of providers to communicate the stresses and strains of NHS contracts to the dentists working for them to justify their relatively high incomes and to retain such staff as performers within the business.

With regard to the implications for policy, our findings highlight the unintended consequences 
associated with the contract in terms of financial considerations influencing treatment decisions. Contract reforms in general medical practice, which create opportunities for gaming the system, do not appear to have resulted in widespread abuse (14). However, the shared perception of the contract amongst members of the dental profession as unfair and unreasonable (in contrast to the new GP contract) appears to have contributed to a sense that gaming the system by choosing the easiest way to meet targets is a legitimate response. Any system that retains a component of activity-based funding will create incentives for dentists to take account of financial considerations in a way that may not be in patients' best interests. Complex scrutiny mechanisms to discourage such behaviour add to costs. Furthermore, some level of professional discretion must be retained for the system to be workable. The challenge is to influence professional values and norms such that abuse of the system (defined in terms of the prioritization of financial rewards over patient interests, which our participants appear to view as acceptable under the current system) is regarded as unacceptable and unprofessional by dentists. Responses to the 2006 contract suggest that many dentists were quick to change behaviour, following its introduction. The coalition government has stated its intention to introduce a new NHS dental contract (15). Our data suggest that part of the process of changing behaviours, norms and attitudes will require the rebuilding of trust in the NHS amongst NHS dentists, as opposed to merely redesigning incentive structures, although the two are related. Whether desired changes of behaviour and norms will be equally swift under the proposed new contract remains to be seen.

\section{References}

1. Smith P. On the unintended consequences of publishing performance data in the public sector. Intl J Pub Admin 1995;18:277-310.

2. Deci EL, Koestner R, Ryan RM. A meta-analytic review of experiments examining the effects of extrinsic rewards on intrinsic motivation. Psychol Bull 1999;125:627-68.

3. Shen Y. Selection incentives in a performance based contracting system. Health Serv Res 2003;38:535-52.

4. Karve AM, Ou FS, Lytle BL, Peterson ED. Potential unintended consequences of pay-for-performance on the quality of care for minority patients. Am Heart J 2008;155:571-6.

5. Calnan M., Silvester S., Manley G., Taylor-Gooby P. Doing Business in the NHS. Exploring dentists' decisions to practice in the public and the private sectors. Sociol Health Illn 2000;22:742-64.

6. Burgess RG. Sponsors, gatekeepers, members, and friends: access in educational settings. In: Shaffir WB, Stebbins RB, editors. Experiencing fieldwork: an inside view of qualitative research. Newbury Park, CA: Sage, 1991; 43-52.

7. Strauss A., Corbin J. Basics of qualitative research: grounded theory procedures and techniques. Thousand Oaks, CA: Sage Publications; 1990.

8. Tickle M., McDonald R., Franklin J., Aggarwal V., Milsom KM., Reeves D. Paying for the wrong kind of performance? Financial incentives and behaviour changes in NHS dentistry 1992-2009 Community Dent Oral Epidemiol 2011;39:465-73.

9. Harris R, Burnside G, Ashcroft A, Grieveson B. Job satisfaction of dental practitioners before and after a change in incentives and governance: a longitudinal study. Br Dent J 2009; 207: E4; discussion 74-5. Epub July 10, 2009.

10. House of Commons Health Committee. Dental Services - Fifth Report of Session 2007-08. The House of Commons 2008, available at: http://www.publications. parliament.uk/pa/cm200708/cmselect/cmhealth/289/ 289i.pdf [last accessed 9 October 2011].

11. Steele J., Clarke J., Rooney E., Wilson T. NHS dental services in England: an independent review. London: Department of Health; 2009.

12. Campbell D. Dentists' earnings leave bad taste in the mouth. The Guardian 2009; Tuesday 4 August.

13. NHS Information Centre. Dental Earnings and Expenses, England and Wales, 2008/09, available at: http:/ / www.ic.nhs.uk/statistics-and-data-collections / primary-care/dentistry/dental-earnings-andexpenses-england-and-wales-2008-09 [last accessed 9th October 2011].

14. Doran T, Fullwood C, Reeves D, Gravelle D, Roland M. Exclusion of patients from pay-for-performance targets by English physicians. $N$ Engl J Med 2008;359:274-84.

15. Department of Health. Equity and excellence: liberating the NHS. Department of Health; 2010, available at: http:/ / www.dh.gov.uk/en/Publicationsandstatistics/Publications/PublicationsPolicyAndGuidance/DH_117353 [last accessed 9th October 2011] 